\title{
Influence of a conductive material and different anaerobic inocula on biochemical methane potential of substrates from alcoholic beverage production
}

\author{
David Valero ${ }^{\mathrm{a}}$, Liliana Alzate-Gaviria ${ }^{\mathrm{a}^{*}}$, Jesús A. Montes ${ }^{\mathrm{b}}$, Carlos Rico ${ }^{\mathrm{b}}$

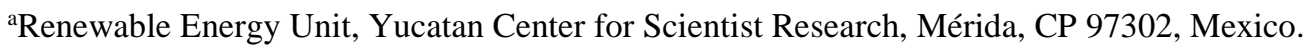 \\ bepartment of Water and Environmental Science and Technologies, University of Cantabria, Avda. Los \\ Castros, s/n, 39005, Santander, Spain. \\ * Corresponding authors. e-mail address: ricoc@unican.es (Carlos Rico) Tel.: +34 942201848; fax: +34 \\ 942201703 and lag@cicy.mx (Liliana Alzate) Tel: +52 9991875379
}

\section{Abstract}

The impact of a conductive material as powdered activated carbon (PAC) on the biochemical methane potential of whisky pot ale (PA) and brewery spent yeast (SY) was investigated. The test was carried out with three different types of anaerobic inocula: manure inoculum (MI), sewage sludge (SS) and granular sludge (GR). Brewery spent yeast produced partial (in sewage and granular sludge) and total (in manure inoculum) methanogenesis inhibition due to the toxicity of some of its constituents (hops extract). The inhibition was overcome by the supplementation of PAC, that improved significantly the anaerobic digestion process for spent yeast, allowing to reach biochemical methane potential values between 657-699 $\mathrm{L} \mathrm{CH}_{4} \mathrm{~kg}^{-1} \mathrm{VS}$ and it reduced redox potential from $-368 \mathrm{mV}$ to $-398 \mathrm{mV}$. The activated carbon did not improve the methane yields from whisky pot ale since microorganisms did not have difficulties to process this substrate; in fact, the redox potential slightly increased from $-355 \mathrm{mV}$ to $-330 \mathrm{mV}$.

Keywords: Biochemical methane potential (BMP); Powdered activated carbon (PAC); Direct interspecies electron transfer (DIET); Anaerobic digestion; Whiskey pot ale; Brewery spent yeast. 


\section{Statement of novelty}

The main novelty of the work is the use of different types of inocula to analyse the effect of the conductive material on the process. To the best of our knowledge there are no previous works in the literature that had performed a similar study. The most important finding is the high methane yield obtained for the brewery spent yeast enhanced by the powdered activated carbon. It is the highest value that can be found in the literature which has been induced by the action of the powdered activated carbon.

\section{Graphical Abstract}

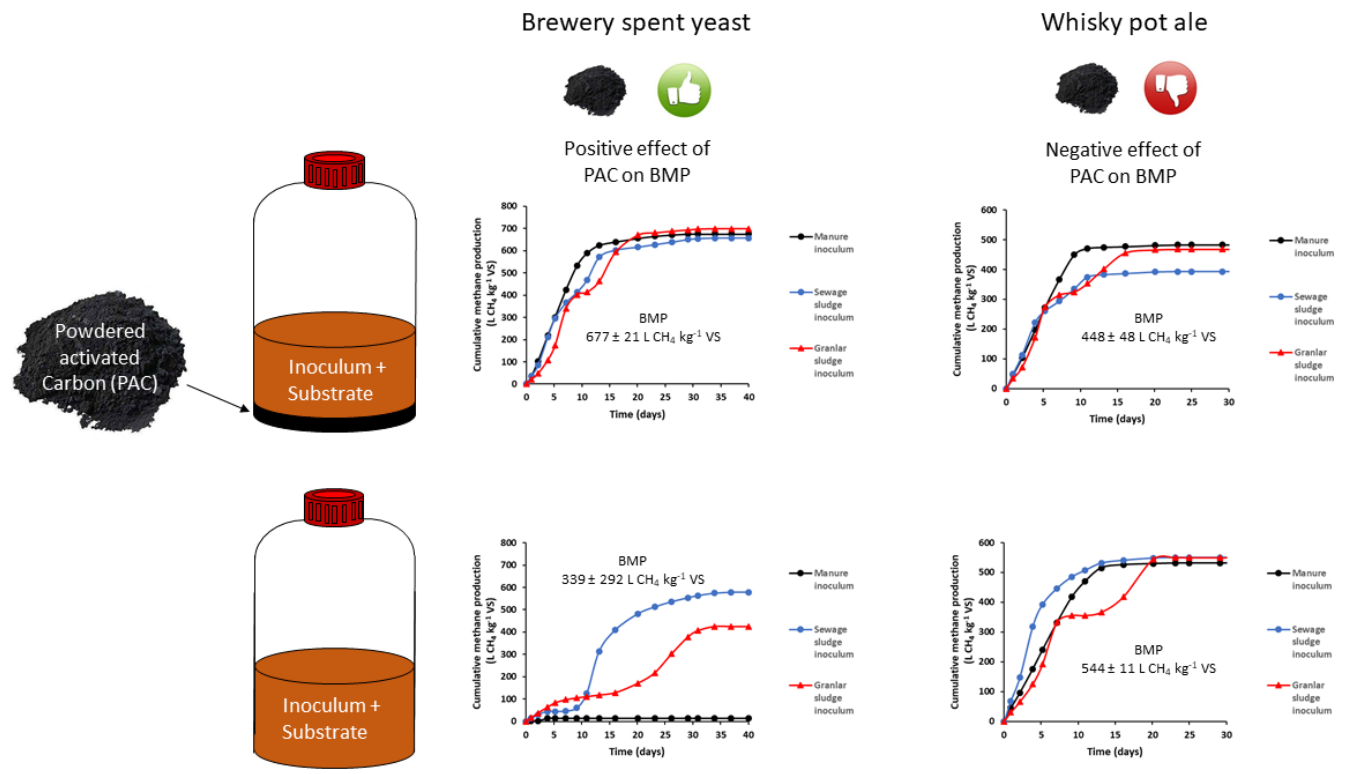




\section{Introduction}

The production of alcoholic beverages is one of the paramount industries around the world, as well as a very important source of organic wastes [1]. Anaerobic digestion (AD) is considered a key method for sustainable waste management and renewable energy production [2].

Anaerobic digestion is a complex process that includes four steps (hydrolysis, acidogenesis, acetogenesis, and methanogenesis) and is performed by a microbial consortia comprising both Eubacteria (hydrolytic-acidogenic bacteria) and acetogenic bacteria (acetogens) and Archaea (hydrogen-utilising methanogens and acetate-utilising methanogens) $[3,4]$. The delicate balance of complex microbial communities can be uncoupled by physiological parameters of the bioreactor and by the presence of toxic compounds that can cause inhibition, leading to process failure $[5,6]$. In this sense, the literature reports two problematic types of organic wastes proceeding from the alcoholic beverage industry that creates difficulties for its anaerobic digestion: whisky pot ale and brewery spent yeast. Barrena et al. [7] justified this limited successful uptake due to problems associated with the high COD (Chemical Oxygen Demand), yeast cells (which sink to the bottom of reactors), inorganic salts, protein (which causes ammonia inhibition) and wide variety of organic compounds including unfermented sugars, that make an stable long term digestion process difficult to achieve [7, 8]. Sosa-Hernández et al. [9] and Zupančič et al. [10] related inhibition problems in the batch anaerobic digestion of brewery spent yeast that resulted in very low methane yield values, which were attributed to the bactericide properties of hops extract.

Likewise, the presence of conductive materials has been demonstrated to improve anaerobic methanogenesis via direct interspecies electron transfer (DIET), inducing lower lag times, better resistance to inhibitory conditions and higher methane yields [11, 
12]. In addition some conductive materials can absorb toxic compounds representing an innovative way to remove and to reduce the effect of the inhibitory compounds for anaerobic bacteria [13]. The DIET has appeared as an alternative pathway to IHT (interspecies hydrogen transfer). In contrast to IHT, DIET pathway allows the electrons to be sent from fermentative bacteria to methanogens even when there is high hydrogen partial pressure. Additionally, DIET circumvents the thermodynamic problems that inhibit the IHT pathway that causes the accumulation of propionate [14]. Most of the previous studies on methanogenic reactors supplemented with conductive materials have used synthetic wastewater as a substrate. Moreover, all of these works have been carried out with only one type of inoculum. Among previous works that used non-synthetic substrates, Zhu et al. [15] studied the anaerobic degradation of coal gasification wastewater with the assistance of graphene, obtaining $24 \%$ and $26 \%$ higher methane yields in batch and upflow anaerobic sludge bed (UASB) reactor continuous operation mode respectively compared to control reactors. Dang et al. [16] used dog food as substrate and carbon cloth and granular activated carbon (GAC) as conductive materials through anaerobic batch assays. They found a significant lag period reduction in reactors amended with carbon cloth or GAC and negligible methane production in the control reactor. Valero et al. [17] studied the methanogenesis of nixtamalization wastewater using GAC as a conductive material in batch tests, with a methane production increase of $54 \%$ compared to the control reactor. Baek et al. [18] assayed the biomethanation of dairy wastewater in batch mode with ferric oxyhydroxide and magnetite as conductive materials. They found a total energy production as biogas in the reactor supplemented with magnetite three times higher than the one in the control reactor. Lei et al. [19] performed a study of UASB anaerobic treatment of leachate from municipal solid waste using carbon-cloth material as conductive material. They observed a better reactor 
performance in the case of the carbon-cloth amended reactor that could operate stably with a 34.2\% higher organic loading rate (OLR) than the control reactor (49.4 vs $36.8 \mathrm{~kg}$ COD m $\mathrm{m}^{-3} \mathrm{~d}^{-1}$ ). In all of these studies the methane production yield, the chemical oxygen demand and VFA removal were all improved by the promotion of DIET through conductive material addition.

The objective of the present work is to study the impact of the supplementation of powdered activated carbon (PAC) on the anaerobic digestion of whisky pot ale and brewery spent yeast and the effect of PAC supplementation on the different types of inocula.

\section{Materials and Methods}

\section{Substrates}

Whisky pot ale (PA) was produced by the authors in the framework of a whisky production study. The brewery spent yeast (SY) was collected from a local brewery. Both PA and SY were stored at $4^{\circ} \mathrm{C}$ until use. The characteristics of the substrates are given in Table 1.

Table 1. Average characteristics of the inocula and substrates used in the study

\begin{tabular}{lccccc}
\hline & \multicolumn{3}{c}{ Inocula } & \multicolumn{3}{c}{ Substrates } \\
\cline { 2 - 6 } & SS & GR & MI & PA & SY \\
TS (\%) & 6.34 & 10.4 & 2.23 & 6.06 & 9.51 \\
VS (\%) & 3.65 & 5.76 & 1.16 & 5.54 & 8.67 \\
COD $\left(\mathrm{g} \mathrm{L}^{-1}\right)$ & --- & --- & --- & 89.7 & 184 \\
$\mathrm{COD} / \mathrm{N}$ & --- & --- & --- & 74.8 & 102 \\
$\mathrm{pH}$ & 7.4 & 7.6 & 7.9 & 4.8 & 5.5 \\
Alkalinity $\left(\mathrm{g} \mathrm{CaCO}_{3} \mathrm{~L}^{-1}\right)$ & 3.3 & 6.8 & 12.1 & -- & --- \\
Total Ammonia Nitrogen $\left(\mathrm{g} \mathrm{NH}_{4}{ }^{+}-\mathrm{N} \mathrm{L}^{-1}\right)$ & 1.2 & 1.6 & 2.7 & 0.2 & 0.2 \\
\hline
\end{tabular}




\section{Inocula and conductive material}

Three different types of inocula have been used for this study: anaerobic sewage sludge (SS) from an anaerobic digester of a wastewater treatment plant, granular biomass (GR) from an lab-scale UASB reactor that had treated pig slurry, and the anaerobic effluent from a lab-scale digester treating liquid dairy manure and food waste (MI-manure inoculum). Characteristics of the inocula can be found in Table 1. PAC (75-150 $\mu$ m) was used as conductive material. Effectiveness of PAC as conductive material in anaerobic digestion has been demonstrated in the work performed by [15, 20].

\section{Experimental set-up: Batch experiments}

All batch experiments were conducted in triplicate in anaerobic $250 \mathrm{~mL}$ serum bottles capped with rubber septum sleeve stoppers. Bottles were filled with the amount of substrate containing $0.5 \mathrm{~g}$ VS and the amount of inoculum to provide an inoculum to substrate ratio of 2 (based on volatile solids). Half of the reactors were added PAC to analyse the differences with and without supplementation of the conductive material. A concentration of $15 \mathrm{~g}$ PAC L ${ }^{-1}$ was used to ensure an effective impact of the conductive material [17]. Thus, twelve different conditions were tested, two substrates processed by three different inocula with and without PAC. The control samples were coded as follows: PA-SS, PA-GR, PA-MI (whisky pot ale with the three inocula), SY-SS, SY-GR, SY-MI (brewery spent yeast with the three inocula). The samples supplemented with activated carbon were coded as follows: PA-SS-PAC, PA-GR-PAC, PA-MI-PAC (whisky pot ale with the three inocula supplemented with powdered activated carbon), SY-SS-PAC, SYGR-PAC, SY-MI-PAC (brewery spent yeast with the three inocula supplemented with powdered activated carbon). Blanks were also tested with and without PAC. After filling the bottles, nitrogen was flushed to remove the oxygen in the headspace of the bottles and thereafter placed in an incubator at $38^{\circ} \mathrm{C}$. The test was stopped for each substrate when 
methane production was negligible in all the samples. Results are expressed as means subtracting methane production from the blanks. Once the experiment was stopped, the reactors were opened to measure the $\mathrm{pH}$, redox potential and VFA in the effluents.

\section{Analytical Techniques}

The biogas and methane production was measured by the manometric method. Headspace pressure was measured in the headspace of the reactors through the septum with a syringe connected to a digital pressure transducer with silicon measuring cell (ifm, Germany - type PN78, up to 2000 mbar). The biogas samples were taken through the septum by a needle connected to a syringe and analyzed on a $2 \mathrm{~m}$ Poropak T column in a HP 6890 gas chromatograph (GC) system with helium as the carrier gas and a TCD detector. The methane volumes are expressed at $0^{\circ} \mathrm{C}$ and $1 \mathrm{~atm}$ in dry conditions. VFA were determined using a HP6890 GC fitted with a 2 m 1/8-in glass column, liquid phase 10\% AT 1000, packed with solid-support Chromosorb W-AW 80/100 mesh. Nitrogen was used as the carrier gas at a flow rate of $14 \mathrm{~mL} / \mathrm{min}$, and a FID detector was installed. Total Solids (TS), Volatile Solids (VS), chemical oxygen demand (COD), total ammonia nitrogen (TAN) and bicarbonate alkalinity were analyzed according to Standard Methods [21].

\section{Data analysis}

Statistical significance was tested by ANOVA analysis, complemented with mean value comparison using Tukey’s HSD tests. Significant difference was determined at p-value of less than $5 \%$.

\section{Results and discussion}

Batch assays with whisky pot ale as substrate 
The batch tests carried out with whisky pot ale showed good degradability of this substrate. Cumulative methane production and daily methane yields for whisky pot ale are depicted in Fig. 1.
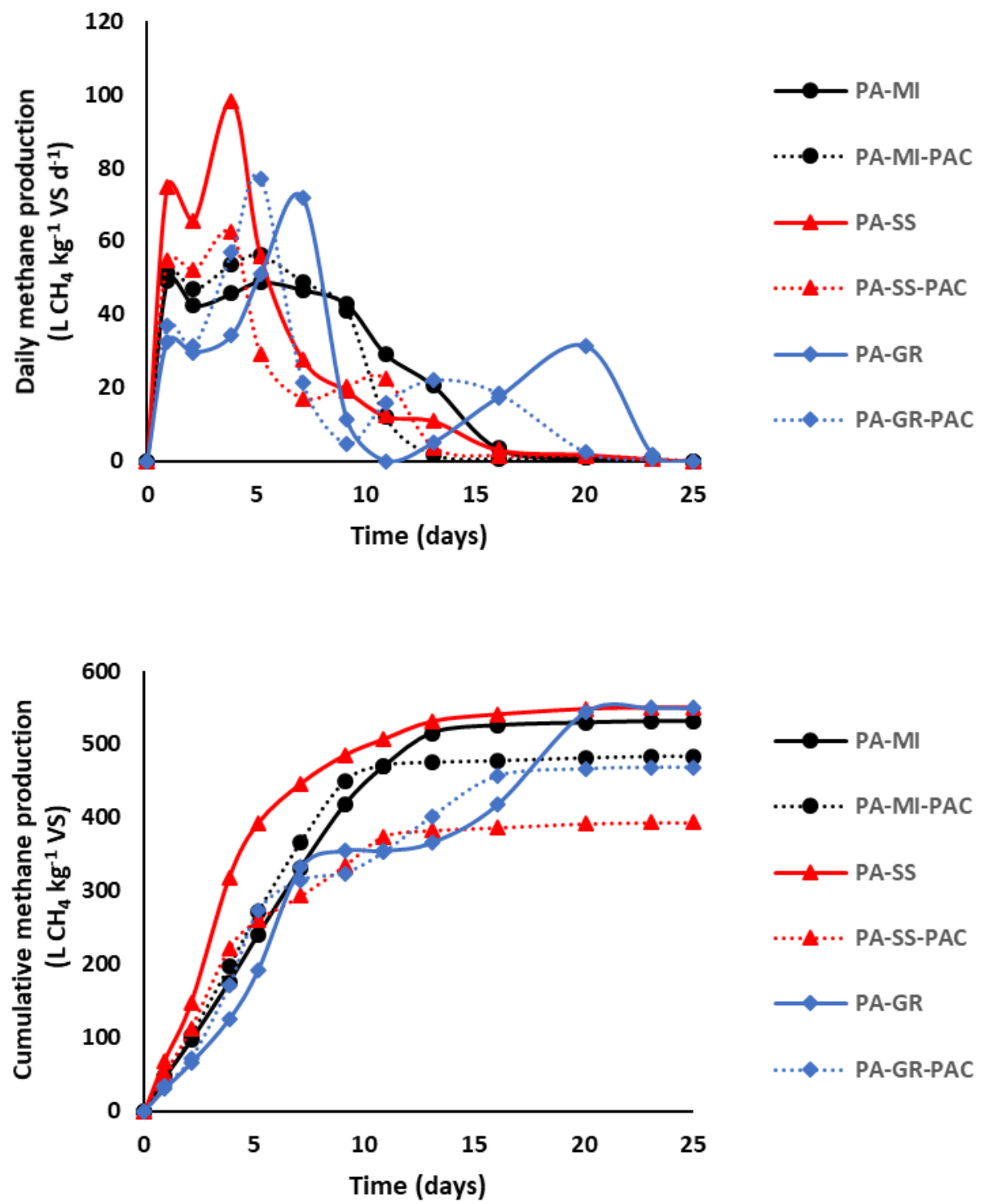

Figure 1. Cumulative specific methane production and daily specific methane production rate for whisky pot ale as substrate. Control reactors: manure (PA-MI), sewage (PA-SS) and granular (PA-GR) sludge inocula. Powdered activated carbon supplemented reactors: manure (PA-MI-PAC), sewage (PA-SS-PAC) and granular (PA-GR-PAC) sludge inocula. 
Control reactors yielded significantly $(\mathrm{p}<0.05)$ higher volumes of methane than reactors supplemented with activated carbon. The specific methane yield values were similar for the three reactors without PAC. The highest values were obtained in reactors inoculated with sewage sludge and granular sludge (550 $\mathrm{L} \mathrm{CH}_{4} \mathrm{~kg}^{-1} \mathrm{VS}$ ), whereas the reactor inoculated with the manure inoculum yielded $531 \mathrm{~L} \mathrm{CH}_{4} \mathrm{~kg}^{-1}$ VS. These results are comparable with others available in the literature, such as that of Barrena et al. [7] who reported a value of $554 \mathrm{~L} \mathrm{CH}_{4} \mathrm{~kg}^{-1}$ VS for whisky pot ale in batch tests. The kinetic behaviour of the three inocula presented some differences in the control reactors, which is consistent with the study performed by Koch et al. [22] who reported that while the methane yield of a given substrate can be comparable between different inocula, the methane production rate can differ significantly.

On the other hand, the reactors supplemented with activated carbon yielded lower methane production values than those of the control ones. In this case, sewage sludge was the inoculum that clearly resulted in the lowest methane yield, with a value of $393 \mathrm{~L} \mathrm{CH}_{4}$ $\mathrm{kg}^{-1} \mathrm{VS}$ (28.5\% lower than the one attained with the same inoculum in the control reactor). The reactors inoculated with granular sludge and manure inoculum produced higher cumulative methane production values (468 and $482 \mathrm{~L} \mathrm{CH}_{4} \mathrm{~kg}^{-1} \mathrm{VS}$ ), which were $14.9 \%$ and 9.2\% lower than those attained with the same inocula in the control reactors. As Table 2 shows, the $\mathrm{pH}$ values were similar in reactors with and without PAC and within the recommended range for anaerobic digestion process. The redox potential values were also similar and within the suitable range for methane formation, with values lower than -250 $\mathrm{mV}$ [4]. With regard to VFA, there were no presence of these compounds in the reactors inoculated with sewage and granular sludge. The absence of VFA in the reactors after the test is indicative of the complete removal of biodegradable organic matter in the media. The presence of VFA at very low concentrations in manure inoculum reactors is useful 
to draw some conclusions. The slightly lower methane yield attained in the control reactor (PA-MI) compared to the other control reactors (PA-SS and PA-GR) can be justified by the very low concentration of VFA remaining in the PA-MI reactor media. The adsorption properties in activated carbon amendments can reduce the bioavailability of some organic compounds. Cheng et al. [8] observed 40-45\% methane yield reductions with activated carbon amendments in the anaerobic digestion of swine wastewater compared with the control reactors. These authors reported that methane yield reduction is the result of a combination of the adsorption properties of the conductive material and the characteristics of the substrate. In this regard, GAC has been employed as a treatment to reduce phenolic compounds and COD concentration before the AD process [23].

Table 2. $\mathrm{pH}$, redox potential and volatile fatty acids after batch test in the reactors fed with whisky pot ale (PA).

\begin{tabular}{lccc}
\hline \multicolumn{1}{c}{ Reactor } & $\mathrm{pH}$ & $\begin{array}{c}\text { Redox potential } \\
(\mathrm{mV})\end{array}$ & $\begin{array}{c}\text { VFA } \\
\left(\mathrm{mg} \mathrm{COD}_{\mathrm{VFA}} \mathrm{L}^{-1}\right)\end{array}$ \\
\hline PA-MI & 7.94 & -368 & 80 \\
PA-MI-PAC & 7.94 & -343 & 120 \\
PA-SS & 7.34 & -320 & 0 \\
PA-SS-PAC & 7.31 & -310 & 0 \\
PA-GR & 7.80 & -355 & 0 \\
PA-GR-PAC & 7.73 & -330 & 0 \\
\hline
\end{tabular}

Control reactors: manure (PA-MI), sewage (PA-SS) and granular (PA-GR) sludge inocula. Powdered activated carbon supplemented reactors: manure (PA-MI-PAC), sewage (PA-SSPAC) and granular (PA-GR-PAC) sludge inocula.

The reactors supplemented with PAC had redox potential higher than control reactors (according to Table 2); obtaining a negative effect of PAC on BMP. This fact is probably due to a more densely populated exoelectrogenic community in the PAC supplemented reactors $[24,25]$. Bacteria and archaea microorganisms have the capacity of to donate and accept electrons through PAC were present in the manure and granular inocula. This 
community have the ability to transform part of the organic matter adsorbed by PAC in methane through DIET pathway, and in doing so it can provide a plausible explanation for the difference in methane production shown between PAC supplemented reactors [25, 26]. Anaerobic granular sludge, a biofilm, is a specialized microenvironment where syntrophic bacterial and archaeal organisms grow together in close proximity. Exoelectrogenic bacteria degrading organic substrates or intermediates need an electron sink and electrotrophic methanogens represent perfect partners to assimilate those electrons and produce methane. The granule extracellular polymeric substances by making the biofilm matrix more conductive, play a role as electrons carrier in DIET [25]. In the case of the whisky pot ale, the powdered activated carbon behaved as an obstacle in $\mathrm{AD}$ because it adsorbed part of the organic matter, reducing the methane production.

\section{Batch assays with brewery spent yeast as substrate}

Anaerobic digestion of brewery spent yeast showed inhibition in the tests performed without the supplementation of activated carbon. For this substrate, reactors supplemented with activated carbon yielded significantly $(\mathrm{p}<0.05)$ higher volumes of methane than the control ones, as Fig. 2 shows. Reactors supplemented with PAC yielded 699, 675 and $657 \mathrm{~L} \mathrm{CH}_{4} \mathrm{~kg}^{-1}$ VS for granular sludge, manure inoculum and sewage sludge respectively. Similar to the results observed in whisky pot ale, sewage sludge was the inoculum supplemented with PAC that gave the lowest methane yield. The cumulative methane production values in the control reactors were significantly lower than those in the PAC reactors. The best performance was observed in the reactor seeded with sewage sludge (SY-SS), which yielded $578 \mathrm{~L} \mathrm{CH}_{4} \mathrm{~kg}^{-1} \mathrm{VS}$ after a lag phase of 10 days. The reactor inoculated with granular sludge (SY-GR) showed two separated peaks in methane production with a final cumulative methane yield of $425 \mathrm{~L} \mathrm{CH}_{4} \mathrm{~kg}^{-1} \mathrm{VS}$. Both behaviours respond to partial inhibition condition and progressive microorganism acclimatisation. 
Moreover, the reactor inoculated with the manure inoculum (SY-MI) produced a negligible volume of methane showing a total inhibition of the methanogenesis.

Table 3. $\mathrm{pH}$, redox potential and volatile fatty acids after batch test in the reactors fed with brewery spent yeast (SY).

\begin{tabular}{lccc}
\hline \multicolumn{1}{c}{ Reactor } & $\mathrm{pH}$ & $\begin{array}{c}\text { Redox potential } \\
(\mathrm{mV})\end{array}$ & $\begin{array}{c}\text { VFA } \\
\left(\mathrm{mg} \mathrm{COD}_{\mathrm{VFA}} \mathrm{L}^{-1}\right)\end{array}$ \\
\hline SY-MI & 7.49 & -359 & 8,650 \\
SY-MI-PAC & 7.91 & -382 & 230 \\
SY-SS & 7.37 & -300 & 892 \\
SY-SS-PAC & 7.38 & -305 & 0 \\
SY-GR & 7.73 & -368 & 4,406 \\
SY-GR-PAC & 7.71 & -398 & 48 \\
\hline
\end{tabular}

Control reactors: manure (SY-MI), sewage (SY-SS) and granular (SY-GR) sludge inocula. Powdered activated carbon supplemented reactors: manure (SY-MI-PAC), sewage (SY-SS-PAC) and granular (SY-GR-PAC) sludge inocula.

The $\mathrm{pH}$, redox potential and VFA measured after methane production ceased are shown in Table 3. As can be seen, differences in pH only occurred in manure inoculum reactors, where $\mathrm{pH}$ of the PAC and the control reactors were 7.91 and 7.49 respectively. Despite the high concentration of VFA in the manure inoculum and granular sludge control reactors, the high alkalinity of those inocula allowed to keep the $\mathrm{pH}$ in a safety range. The redox potential values were similar in all the reactors and the main differences were detected in the VFA concentration; not only in the total VFA concentration, but also in the contribution of individual VFA. PAC supplemented reactors presented negligible VFA concentrations. With regard to control reactors, as expected from methane yield values, the sewage sludge (SY-SS) performed the best, with VFA concentration of 892 mg CODVFA $\mathrm{L}^{-1}$, being propionic the predominant VFA (665 mg COD L ${ }^{-1}$ ). The reactor inoculated with granular sludge (SY-GR) had a VFA concentration of 4,406 CODVFA $\mathrm{L}^{-}$ ${ }^{1}$, with propionic $\left(3,844 \mathrm{mg} \mathrm{COD} \mathrm{L}^{-1}\right)$ as the individual VFA with the highest contribution. 

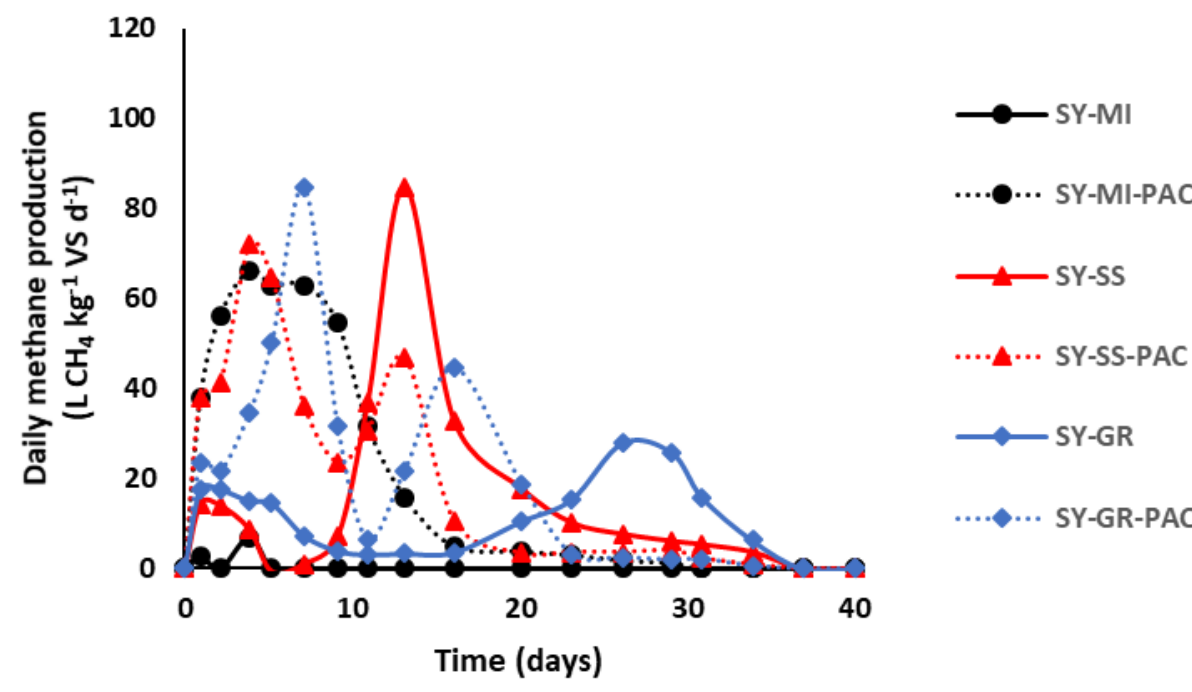

....... SY-SS-PAC

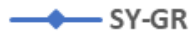

...... SY-GR-PAC

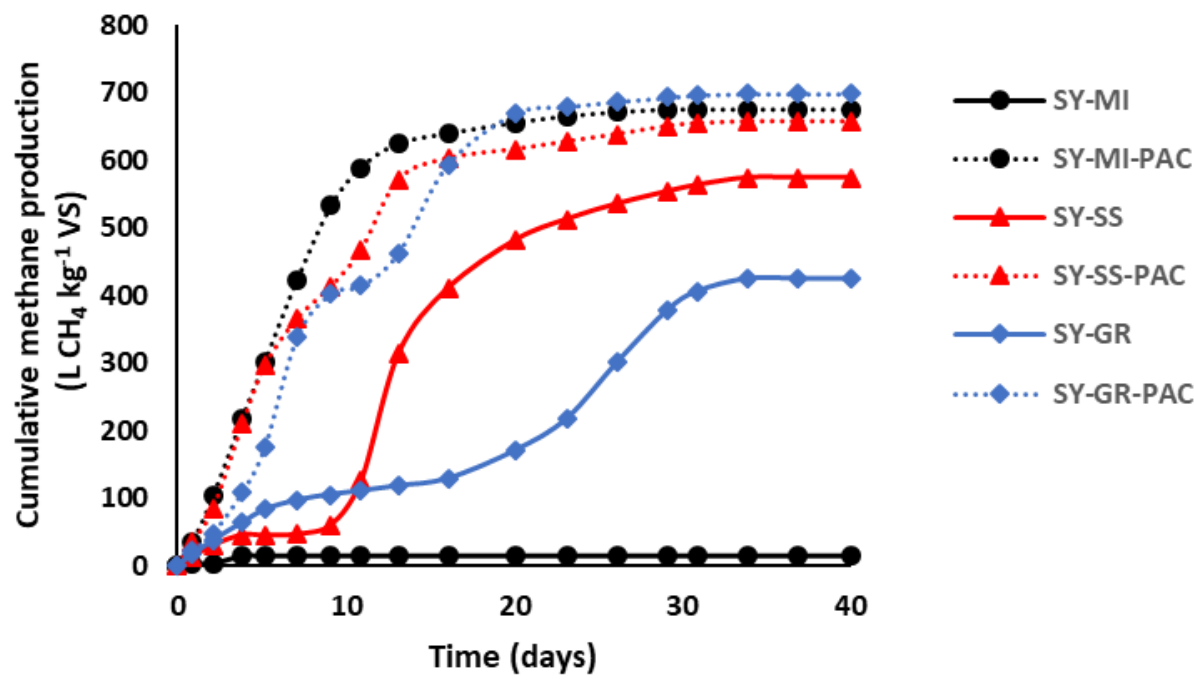

Figure 2. Cumulative specific methane production and daily specific methane production rate for brewery spent yeast as substrate. Control reactors: manure (SY-MI), sewage (SYSS) and granular (SY-GR) sludge inocula. Powdered activated carbon supplemented reactors: manure (SY-MI-PAC), sewage (SY-SS-PAC) and granular (SY-GR-PAC) sludge inocula. 
As expected from the negligible methane yield obtained in the manure inoculum reactor (SY-MI), this reactor resulted in the highest VFA concentration $\left(8,648 \mathrm{mg} \mathrm{CODVFA}^{-1}\right)$. Different from VFA distribution in granular inoculum reactor, acetic $\left(6,538 \mathrm{mg} \mathrm{COD} \mathrm{L}^{-}\right.$ ${ }^{1}$ ) was the predominant VFA, followed by propionic (920 mg COD L ${ }^{-1}$ ). The remaining VFA concentrations in the control reactors confirm methanogenesis inhibition and explain the different methane yield values compared with PAC reactors. In the reactor seeded with manure inoculum, a high accumulation of acetic acid was produced, therefore, predominant acetoclastic methanogens community are more sensitive to acetic acid accumulation than a hydrogenotrophic methanogens community [27].

There are a few previous studies on anaerobic digestion with or without DIET of brewery spent yeast. Vitanza et al. [28] reported a methane yield of $594 \mathrm{~L} \mathrm{CH}_{4} \mathrm{~kg}^{-1} \mathrm{VS}$ in batch tests, but these authors used a much higher inoculum to substrate ratio (between 9 and 24 in terms of VS) to reduce reaction time that may have masked inhibition problems. Oliveira et al. [30] reported a methane yield of $515 \mathrm{~L} \mathrm{CH}_{4} \mathrm{~kg}^{-1} \mathrm{VS}$ for the brewery spent yeast. They used an inoculum previously adapted to brewery wastewaters and an inoculum to substrate ratio of 2.5. On the other hand, Sosa-Hernández et al. [9] related inhibition problems in the batch anaerobic digestion of brewery spent yeast that resulted in very low methane yield values. Zupančič et al. [10] also reported negative impacts through anaerobic co-digestion of brewery spent yeast and brewery wastewaters at spent yeast proportions higher than $2.8 \%$ in the mixture. In this sense, the bactericide properties of hops extract may be responsible for these inhibition problems [9] and PAC supplementation has demonstrated to be a solution to overcome the inhibition of the process. The methane yields of the brewery spent yeast obtained in the present work in the reactors supplemented with PAC (657-699 $\left.\mathrm{L} \mathrm{CH}_{4} \mathrm{~kg}^{-1} \mathrm{VS}\right)$ are higher than any other in the literature for this substrate. Moreover, the results show that the addition of 
conductive materials avoided VFA accumulation and consequently the anaerobic digestion process inhibition. When the electron transfer is produced through DIET pathway, the speed of the process is increased [14]. It has been widely reported that the acetoclastic methanogens can be an electron acceptor and reduce carbon dioxide to methane when they are attached to conductive carbon materials and work as electrotrophic partner in DIET [31].

Zhu et al. [15] observed improvement in the anaerobic degradation of coal gasification wastewater with the assistance of graphene, which was justified by a reduction in the methanogens inhibition by toxic compounds in the wastewater. In that work, the graphene was useful to overcome the toxicity of the substrate. In another study, Dang et al. [32] observed a significant improvement in anaerobic digestion performance in reactors amended with carbon cloth and GAC using food dog, which is used as a representative source of food wastes, as substrate. In this case, rather than toxicity of the substrate, the low inoculum to substrate ratio ( 0.14 based on VS, calculated from data of substrate and inoculum) could have caused an over-acidification and a negligible production of methane in the control reactors that was overcome by the conductive materials. The same substrate (dog food) was successfully processed without the presence of conductive materials in the work performed by Koch et al. [33] with an inoculum to substrate ratio of 2 (based on VS), attaining methane yields about $450 \mathrm{~L} \mathrm{CH}_{4} \mathrm{~kg}^{-1} \mathrm{VS}$ with three different inocula. Similarly, in the work carried out by Baek et al. [18] the enhancement in the anaerobic digestion performance of dairy wastewater assisted by conductive material was more a consequence of the low inoculum to substrate ratio ( 0.17 based on VS, calculated from data of substrate and inoculum) than the toxicity of the substrate. This effect would be applicable to high organic loading rates in anaerobic continuous operation processes, as reported in the work performed by Lei et al. [19]. These authors processed an easily 
biodegradable wastewater with high organic content and the use of carbon cloth as conductive material allowed to operate stably with a $34.2 \%$ higher organic loading rate than the control system.

The use of powdered activated carbon improved anaerobic digestion performance for brewery spent yeast, a problematic substrate, providing better resistance to inhibitory conditions.

\section{Conclusions}

Powdered activated carbon improved the anaerobic digestion of brewery spent yeast, a waste that inhibited methanogenesis when the conductive material was not incorporated into the media. On the contrary, powdered activated carbon did not improve methane yields for whisky pot ale, a substrate that was easily processed by anaerobic inocula. The activated carbon was an obstacle for anaerobic digestion of a waste that did not show inhibition properties, especially when sewage anaerobic sludge was used as inoculum, because its adsorption properties reduced the bioavailability of some organic compounds, reducing the methane production. The results showed that conductive materials are beneficial for anaerobic digestion in presence of inhibitory compounds and high organic loading rates operating condition that can lead to over-acidification in the anaerobic digestion process.

\section{Acknowledgements}

This research was supported by Destilería Siderit in the framework of the Innova Program in the Autonomous Community of Cantabria. 


\section{References}

1. Montes, J.A., Leivas, R., Martínez-Prieto, D., Rico, C.: Biogas production from the liquid waste of distilled gin production: Optimization of UASB reactor performance with increasing organic loading rate for co-digestion with swine wastewater. $\begin{array}{llll}\text { Bioresour. } & \text { Technol. } & \text { 274, } & 43-47\end{array}$ https://doi.org/10.1016/j.biortech.2018.11.060

2. Massara, T. M., Komesli, O. T., Sozudogru, O., Komesli, S., \& Katsou, E.: A Mini Review of the Techno-environmental Sustainability of Biological Processes for the Treatment of High Organic Content Industrial Wastewater Streams. Waste Biomass Valoriz. 8(5), 1665-1678 (2017). https://doi.org/10.1007/s12649-017-0022-y

3. Zahedi, S., Sales, D., García-Morales, J.L., \& Solera, R.: Obtaining green energy from dry-thermophilic anaerobic co-digestion of municipal solid waste and biodiesel $\begin{array}{llll}\text { waste. } & \text { Biosyst. } & \text { Eng. } & \text { 170, }\end{array}$ https://doi.org/10.1016/j.biosystemseng.2018.04.005

4. Deublein, D., \& Steinhauser, A.: Biogas from Waste and Renewable Resources: an Introduction. John Wiley \& Sons, pp. 100 (2011).

5. Chen, Y., Cheng, J.J., \& Creamer, K.S.: Inhibition of anaerobic digestion process: a review. Bioresour. Technol. 99, 4044-4064 (2008). https://doi.org/10.1016/j.biortech.2007.01.057

6. Calabrò, P.S., Fazzino, F., Folino, A., Scibetta, S. \& Sidari, R.: Improvement of semicontinuous anaerobic digestion of pre-treated orange peel waste by the combined use of zero valent iron and granular activated carbon. Biomass Bioenerg. 129, 105337 (2019). https://doi.org/10.1016/j.biombioe.2019.105337

7. Barrena, R., Traub, J.E., Rodriguez Gil, C., Goodwin, J.A.S., Harper, A.J., Willoughby, N.A., Sánchez, A., \& Aspray, T.J.: Batch anaerobic digestion of 
deproteinated malt whisky pot ale using different source inocula. Waste Manag. 71, 675-682 (2018). https://doi.org/10.1016/j.wasman.2017.06.025

8. Cheng, Q., de los Reyes, \& Call, D.F.: Amending anaerobic bioreactors with pyrogenic carbonaceous materials: the influence of material properties on methane generation. Environ. Sci.: Water Res. Technol. 4, 1794-1806 (2018). https://doi.org/10.1039/C8EW00447A

9. Sosa-Hernández, O., Parameswaran, P., Alemán-Nava, G.S., Torres, C.I., \& Parra-Saldívar, R.: Evaluating biochemical methane production from brewer’s spent yeast. J. Ind. Microbiol. Biotechnol. 43, 1195-1204 (2016). https://doi.org/10.1007/s10295-016-1792-0

10. Zupančič, G.D., Škrjanec, I., \& Logar, R.M.: Anaerobic co-digestion of excess brewery yeast in a granular biomass reactor to enhance the production of biomethane. $\begin{array}{llll}\text { Bioresour. } & \text { Technol. } & \text { 324, } & \end{array}$ (2012). https://doi.org/10.1016/j.biortech.2012.08.064

11. Kato, S., Hashimoto, K., \& Watanabe, K.: Methanogenesis facilitated by electric syntrophy via (semi) conductive iron-oxide minerals. Environ. Microbiol. 14, 16461654 (2012). https://doi.org/10.1111/j.1462-2920.2011.02611.x

12. Zema, D.A., Fòlino, A., Zappia, G., Calabrò, P.S., Tamburino, V. \& Zimbone, S.A.: Anaerobic digestion of orange peel in a semi-continuous pilot plant: An environmentally sound way of citrus waste management inagro-ecosystems. Sci. Total Environ. 630, 401-408 (2018). https://doi.org/10.1016/j.scitotenv.2018.02.168

13. Calabrò, P.S., Fazzino, F., Folino, A., Paone, E. \& Komilis, D.: Semi-continuous anaerobic digestion of orange peel waste: effect of activated carbon addition and alkaline pretreatment on the process. Sustainability 11, 3386 (2019). https://doi.org/10.3390/su11123386 
14. Cruz Viggi, C., Rossetti, S., Fazi, S., Paiano, P., Majone, M., Aulenta, F.: Magnetite particles triggering a faster and more robust syntrophic pathway of methanogenic propionate degradation. Environ. Sci. Technol. 48 (13), 7536-7543 (2014). https://doi.org/10.1021/es5016789

15. Zhu, H., Han, Y., Ma, W., Han, H., Ma, W. \& Xu, C.: New insights into enhanced anaerobic degradation of coal gasification wastewater (CGW) with the assistance of $\begin{array}{llll}\text { graphene. Bioresour. } & \text { Technol. } & \text { 262, } & \text { 302-309 }\end{array}$ https://doi.org/10.1016/j.biortech.2018.04.080

16. Dang, Y., Sun D., Woodard, T.L., Wang, L.Y., Nevin, K.P., \& Holmes, D.E.: Stimulation of the anaerobic digestion of the dry organic fraction of municipal solid waste (OFMSW) with carbon-based conductive materials. Bioresour. Technol. 238, 30-38 (2016). https://doi.org/10.1016/j.biortech.2017.04.021

17. Valero, D., Rico, C., Canto-Canché, B., Domínguez-Maldonado, J., Tapia-Tussell, R., Cortes-Velazquez, A., \& Alzate-Gaviria, L.: Enhancing Biochemical Methane Potential and Enrichment of Specific Electroactive Communities from Nixtamalization Wastewater using Granular Activated Carbon as a Conductive Material. Energies. 11(8), 2101 (2018). https://doi.org/10.3390/en11082101

18. Baek, G., Kim, J., Cho, K., Bae, H., \& Lee, C.: The biostimulation of anaerobic digestion with (semi)conductive ferric oxides: their potential for enhanced biomethanation. Appl. Microbiol. Biotechnol. 99, 10355-10366 (2015). https://doi.org/10.1007/s00253-015-6900-y

19. Lei, Y., Sun, D., Dang, Y., Chen, H., Zhao, Z., Zhang, Y., \& Holmes, D.E.: Stimulation of methanogenesis in anaerobic digesters treating leachate from a municipal solid waste incineration plant with carbon cloth. Bioresour. Technol. 222, 270-276 (2016). https://doi.org/10.1016/j.biortech.2016.10.007 
20. Xu, S., He, C., Luo, L., Lü, F., He, P., Cui, L.: Comparing activated carbon of different particle sizes on enhancing methane generation in upflow anaerobic digester. Bioresour. $\quad$ Technol. 196, 606-612 https://doi.org/10.1016/j.biortech.2015.08.018

21. APHA: Standard Methods for the Examination of Water and Wastewater, 20th edn. American Public Health Association, Washington, USA (1998).

22. Koch, K., Lippert, T., \& Drewes, J.E.: The role of inoculum's origin on the methane yield of different substrates in biochemical methane potential (BMP) tests. Bioresour. Technol. 243, 457-463 (2017). https://doi.org/10.1016/j.biortech.2017.06.142

23. Shanmugam, S.R., Adhikari, S., Wang, Z., \& Shakya, R.: Treatment of aqueous phase of bio-oil by granular activated carbon and evaluation of biogas production. $\begin{array}{lllll}\text { Bioresour. } & \text { Technol. } & \text { 223, } & \text { 115-120 }\end{array}$ https://doi.org/10.1016/j.biortech.2016.10.008

24. Camacho, C. G., \& Ruggeri, B.: Syntrophic Microorganisms Interactions in Anaerobic Digestion (AD): a Critical Review in the Light of Increase Energy Production. Chem. Eng. Trans. 64, 391-396 (2018).

25. Dubé, C. D., \& Guiot, S. R. (2015). Direct interspecies electron transfer in anaerobic digestion: a review. In Guebitz G., Bauer A., Bochmann G., Gronauer A., Weiss S. (eds) Biogas Science and Technology. Advances in Biochemical Engineering/Biotechnology, vol 151. Springer, Cham. https://doi.org/10.1007/978-3$\underline{319-21993-6 \_4}$

26. Goodwin, J. A. S., \& Stuart, J. B.: Anaerobic digestion of malt whisky distillery pot ale using upflow anaerobic sludge blanket reactors. Bioresour. Technol. 49(1), 75-81 (1994). https://doi.org/10.1016/0960-8524(94)90175-9

27. Franke-Whittle, I. H., Walter, A., Ebner, C., \& Insam, H.: Investigation into the effect 
of high concentrations of volatile fatty acids in anaerobic digestion on methanogenic

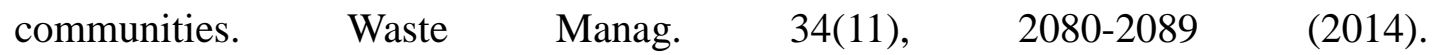
https://doi.org/10.1016/j.wasman.2014.07.020

28. Atelge, M. R., Krisa, D., Kumar, G., Eskicioglu, C., Nguyen, D. D., Chang, S. W., Atabani, A.E., Al-Muhtaseb. A.H., \& Unalan, S.: Biogas Production from Organic Waste: Recent Progress and Perspectives. Waste Biomass Valoriz. 1-22 (2018). https://doi.org/10.1007/s12649-018-00546-0

29. Vitanza, R., Cortesi, A., Gallo, V., Colussi, I., \& De Arana-Sarabia, M.E.: Biovalorization of brewery waste by applying anaerobic digestion. Chem. Biochem. Eng. Q. 30, 351-357 (2016). https://doi.org/10.15255/CABEQ.2015.2237

30. Oliveira, J.V., Alves, M.M., \& Costa, J.C.: Biochemical methane potential of brewery by-products. Clean Technol. Envir. 20, 435-440 (2018). https://doi.org/10.1007/s10098-017-1482-2

31. Barua, S., Dhar, B. R.: Advances towards understanding and engineering direct interspecies electron transfer in anaerobic digestion. Bioresour. Technol. 244, 698707 (2017). https://doi.org/10.1016/j.biortech.2017.08.023

32. Dang, Y., Holmes, D. E., Zhao, Z., Woodard, T. L., Zhang, Y., Sun, D., ... \& Lovley, D. R.: Enhancing anaerobic digestion of complex organic waste with carbon-based conductive materials. Bioresour. Technol. 220, 516-522 (2016). https://doi.org/10.1016/j.biortech.2016.08.114

33. Koch, K., Lippert, T., Drewes, J.E.: The role of inoculum's origin on the methane yield of different substrates in biochemical methane potential (BMP) tests. Bioresour. Technol. 243, 457-463 (2017). https://doi.org/10.1016/j.biortech.2017.06.142 